\title{
POLÍTICAS DE ACCOUNTABILITY NA EDUCAÇÃO CEARENSE (2007-2019)
}

\author{
Arlane Markely dos Santos Freirel \\ Andréia Ferreira da Silva²
}

\begin{abstract}
RESUMO
O artigo analisa o processo de implantação e de consolidação das políticas de accountability na educação pública cearense, refletindo acerca das relações estabelecidas entre governos estadual e municipais neste processo. Apresenta as principais políticas de accountability adotadas no estado. Resulta de revisão bibliográfica sobre a temática proposta e da análise de documentos legais e normativos da política educacional cearense. Numa perspectiva gerencialista da gestão por resultados, o governo do estado do Ceará implantou políticas que articulam medidas de avaliação externa em larga escala, de responsabilização e de prestação de contas que envolvem as redes estadual e municipais de ensino. Tem atuado como regulador e avaliador da educação municipal por meio da implantação de um regime de colaboração "sob condicionalidades" (FREITAS, 2007), orientado para o alcance de metas e o pagamento de bonificações.
\end{abstract}

Palavras-chave: Políticas de accountability. Gestão por resultados. Educação Básica. Estado do Ceará.

\section{ACCOUNTABILITY POLICIES IN CEARÁ EDUCATION (2007-2019)}

\begin{abstract}
The paper analyzes the process of implementation and consolidation of accountability policies in public education in Ceará reflecting on the relationships

\footnotetext{
1 Mestra em Educação pelo Programa de Pós-Graduação em Educação da Universidade Federal de Campina Grande (PPGEd/UFCG). Professora da rede pública do município de Crato/CE, Brasil. Membro do Grupo de Estudos em Política e Gestão Educacional, que integra - Laboratório de Pesquisa em Políticas Educacionais da UFCG (LEPPE/UFCG). Vice-diretora estadual da Associação Nacional de Política e Administração da Educação (ANPAE), seção Ceará, sendo eleita para o biênio 2021-2023.Orcid iD: https://orcid.org/0000-0003-3929-1629. E-mail: arlanemarkely@yahoo.com.br

2 Doutora em Educação pela Universidade Federal Fluminense (UFF) (2004). Pós-doutoranda Faculdade de Educação/Universidade Estadual de Campinas (UNICAMP). Professora Associada da UFCG e docente permanente do PPGEd/UFCG, Campina Grande/PB, Brasil. Coordenadora do Grupo de Estudos em Política e Gestão Educacional, que integra o Laboratório de Pesquisa em Políticas Educacionais da UFCG (LEPPE/UFCG). Orcid iD: https://orcid.org/0000-0001-9574-3808. E-mail: silvaandreia@uol.com.br
} 
established between state and municipal governments in this process. It presents the main accountability policies adopted in the state. It results from a literature review on the proposed theme and the analysis of legal and normative documents of the educational policy of Ceará. From a managerial perspective of management for results, the government of the state of Ceará has implemented policies that articulate large-scale external evaluation, responsibility and accountability measures that involve the state and municipal education systems. It has acted as regulator and evaluator of municipal education through the implementation of a collaboration regime "under conditionalities" (FREITAS, 2007), aimed at achieving goals and paying bonuses.

Keywords: Accountability policies. Management by results. Basic education. State of Ceará.

\section{POLÍTICAS DE RENDICIÓN DE CUENTAS EN LA EDUCATIÓN DEL CEARÁ}

(2007-2019)

\section{RESUMEN}

El artículo analiza el proceso de implementación y consolidación de las políticas de rendición de cuentas en la educación pública en Ceará, reflexionando sobre las relaciones que se establecen entre los gobiernos estatales y municipales en este proceso. Presenta las principales políticas de rendición de cuentas adoptadas en el estado. Es el resultado de una revisión de la literatura sobre el tema propuesto y el análisis de documentos legales y normativos de la política educativa de Ceará. Desde una perspectiva gerencial de gestión por resultados, el gobierno del estado de Ceará ha implementado políticas que articulan medidas de evaluación externa, rendición de cuentas y rendición de cuentas a gran escala que involucran a las redes educativas estatales y municipales. Ha actuado como regulador y evaluador de la educación municipal a través de la implementación de un régimen de colaboración "bajo condicionalidades" (FREITAS, 2007), orientado al logro de metas y al pago de bonificaciones.

Palabras clave: Políticas de rendición de cuentas. Gestión por resultados. Educación básica. Estado de Ceará.

\section{INTRODUÇÃO}

O presente texto analisa as políticas de accountability adotadas no setor educacional pelo governo do estado do Ceará, a partir de 2007, que têm se consolidado como mecanismo de regulação da educação básica cearense. A implantação dessas medidas está vinculada ao contexto de fortalecimento da ideologia neoliberal no país, a partir dos anos de 1990, que fomentou processos de reforma do Estado e da educação marcados pelos princípios da nova gestão pública. No Brasil, o processo de reformas teve início 
durante os mandatos presidenciais de Fernando Collor de Melo (1990-1992) e Itamar Franco (1992-1994), por meio da instituição de políticas de liberalização da economia e de privatização. A partir do mandato de Fernando Henrique Cardoso (1995-2002), a implementação dessas reformas foi consolidada, favorecendo ainda mais a lógica do capital, de acordo com as orientações constantes no Plano Diretor da Reforma do Aparelho do Estado (1995).

No Ceará, segundo Barbalho (2007), os processos de reforma foram conduzidos por setores empresariais, que se apresentaram em oposição aos grupos políticos que governaram o estado até a segunda metade da década de 1980, estabelecendo um movimento conhecido como mudancismo. Para - autor, nesse contexto, foi estabelecida uma polarização entre os empresários que representavam a modernidade versus os políticos tradicionais, os coronéis, que representavam a tradição. Comprometidos com a adequação do estado às demandas da modernização da produção capitalista, e da educação, ao padrão de sociabilidade requerido por essas mudanças, tanto do ponto de vista técnico quanto ético, o "movimento mudancista" teve início no primeiro mandato do governador Tasso Jereissati, em 1986 (BARBALHO, 2007; NOBRE, 2008).

De acordo com Oliveira (2018), as propostas que orientaram os "Governos das Mudanças", vinculados ao Partido da Social Democracia Brasileira (PSDB), de Tasso Jereissati (1987-1990; 1995-1998; 1999-2002), Ciro Gomes (1991-1994), Lúcio Alcântara (2003-2006) e Cid Gomes (2007-2010; $2011-2014$ ), foram mantidas e ampliadas no governo de Camilo Santana, do Partido dos Trabalhadores (PT), que teve seu primeiro mandato entre 2015 a 2018, sendo reeleito para governar o Ceará de 2019 a 2022.

Na educação, segundo Ramos, Lira e Soares (2012), a reforma gerencial cearense, a partir dos anos de 1990, adotou o modelo de gestão da qualidade total, visando classificar, mensurar e comparar as unidades escolares, implantando a proposta de gestão por resultados. Ao adotar a Gestão por Resultados (GpR) na administração pública, o governo do estado do Ceará implementou, a partir de 2007, políticas de accountability no setor educacional, constituindo-se, a partir de então, em referência nacional na 
adoção de políticas de avaliação externa em larga escala vinculadas à instituição de iniciativas de premiação de docentes, escolas, redes de ensino e municípios.

No Brasil, a implantação de iniciativas de accountability integra as proposições da Nova Gestão Pública (NGP), que propõe a implantação do modelo de gestão da empresa privada no setor público por meio, entre outros, da instituição de mecanismos de avaliação externa dos resultados e da concessão de bonificação pelo alcance das metas. Nesta proposta, a accountability tem um fim em si mesma, que é favorecer a maior eficiência, efetividade e eficácia na administração dos bens públicos (SCHNEIDER; NARDI, 2015).

No campo educacional, de acordo com Afonso (2007; 2009b), o termo accountability tem sido utilizado para se referir às políticas de bonificação ou de responsabilização dos agentes públicos pelos resultados nas avaliações externas. No entanto, para o autor, tais políticas podem ter um sentido mais amplo, expressas em modelos e sistemas comprometidos com o fortalecimento dos mecanismos coletivos de controle social da qualidade dos serviços educativos públicos.

Para Afonso (2009a), o conceito de accountability é constituído por três dimensões articuladas e articuláveis: avaliação externa, responsabilização e prestação de contas. A dimensão da avaliação diz respeito ao processo de recolha, de tratamento e de análise de informações, consistindo em condição indispensável nos processos de prestação de contas e de responsabilização. A responsabilização refere-se ao grau de recompensas, às formas de indução e às normas de conduta, à imputação de responsabilidades e à imposição de sanções ou a atribuição de recompensas materiais e simbólicas. A prestação de contas consiste na dimensão informativa e de publicização dos resultados (AFONSO, 2009b).

Considerando o exposto, o artigo está organizado em três partes, além da presente introdução. Na primeira parte, expõe a reforma do setor educacional cearense, apontando os antecedentes da reforma que viabilizaram a implantação das políticas de accountability a partir de 2007. Em 
seguida, examina as principais medidas adotadas no estado, que contribuíram para a instituição de uma política de accountability que envolve as redes estadual e municipais de ensino: o Sistema Permanente de Avaliação da Educação Básica do Ceará (Spaece); o Programa de Alfabetização na Idade Certa (Paic); a reformulação dos critérios para a distribuição do Imposto sobre Operações Relativas à Circulação de Mercadorias e sobre Prestações de Serviços de Transporte Interestadual, Intermunicipal e de Comunicação (ICMS); e o estabelecimento de premiações de âmbito estadual com base nos resultados do Spaece, Prêmio Escola Nota Dez, Prêmio Aprender pra Valer e Prêmio Foco na Aprendizagem. Por fim, as considerações finais.

O texto resulta de revisão bibliográfica e da análise de documentos. A revisão bibliográfica contemplou o estudo da produção acadêmica que discute as políticas de avaliação externa e as políticas de accountability no Brasil e no estado do Ceará a partir dos anos de 1990. A análise de documentos, fonte principal dos dados que fundamentam o trabalho, foi realizada por meio de um amplo levantamento e estudo dos documentos legais e normativos que regulamentam as políticas de accountability implantadas na educação pública cearense, sob a responsabilidade do governo estadual. Os documentos foram analisados tendo como referência a compreensão, segundo Evangelista (2012), de que expressam não apenas diretrizes para a educação, mas articulam interesses, projetam políticas e produzem intervenções sociais.

\section{REFORMA DA EDUCAÇÃO NO ESTADO DO CEARÁ: IMPLANTAÇÃO DA GESTÃO POR RESULTADOS (GPR) E DE POLÍTICAS DE ACCOUNTABILITY}

No estado do Ceará, o processo de reforma, a partir da década de 1990, teve como elementos centrais as mudanças ocorridas na gestão pública com a implantação dos princípios do gerencialismo e da GpR. A seguir é apresentado o processo de implantação e de consolidação das políticas de accountability no âmbito estadual e as relações estabelecidas entre governos estadual e municipais neste processo. 


\section{Gerencialismo na educação e antecedentes das políticas de accountability no estado do Ceará (1986-2007)}

No Ceará, a reforma da aparelhagem estatal ocorreu, inicialmente, no Governo de Tasso Jereissati, eleito em 1986 para seu primeiro mandato, filiado até o ano de 1990 ao Partido do Movimento Democrático Brasileiro (PMDB) e, posteriormente, ao PSDB. Como governador teve três gestões: 1987 a 1990; 1995 a 1998; e 1999 a 2002. Nobre (2008) denomina esse período de "Era Tasso", que engloba também a gestão de Ciro Gomes (PSDB-CE), de 1991 a 1994. Em 2002, foi eleito Lúcio Alcântara (PSDB-CE) para o período 2003-2006, cuja administração não contou com o apoio direto do grupo empresarial vinculado à "Era Tasso", mesmo mantendo as políticas econômicas de sustentação ao grande capital (NOBRE, 2008)3.

No que se refere à educação, o governo de Tasso Jereissati (PSDB-CE) se destacou pela implantação da municipalização da oferta do ensino fundamental, por meio da aprovação da Lei n. ${ }^{\circ}$ 12.452, de 6 de junho de 1995, pelo estabelecimento da eleição direta de diretores escolares e pela criação do Projeto Escola do Novo Milênio (PENM). Esse Projeto tinha o objetivo de assegurar um padrão de qualidade, eficiência e equidade na prestação dos serviços educacionais, viabilizado por um empréstimo com $\circ$ Banco Internacional de Reconstrução e Desenvolvimento (BIRD) - Contrato de Empréstimo de número 4591-BR, em 2002 (RAMOS; LIRA; SOARES, 2012).

Nesse período, conforme Aguiar (2002), ocorreram, também, processos de cooperação técnica entre o governo do estado do Ceará e municípios que privilegiaram questões relativas à macro política educacional, como a criação das Coordenadorias Regionais de Desenvolvimento da Educação (CREDES), em 1996. Foram firmados, ainda, projetos que favoreceram o estabelecimento de parcerias entre a esfera pública e a privada e ações interinstitucionais, que contribuíram para o fortalecimento do gerencialismo

\footnotetext{
${ }^{3}$ A matriz gerencialista, que influenciou os governos estaduais, emergiu antes do período de 1986 a 2006, "remontando ao tempo em que um grupo de empresários, organizados em torno do Centro Industrial do Ceará $(\mathrm{ClC})$, projetou o desenvolvimento estadual para o interstício de 1985 a 2005" (RAMOS et al., 2018, p. 8).
} 
na educação do estado. As diretrizes políticas da modernização da gestão estavam pautadas no fortalecimento do controle social e institucional, com ênfase no fortalecimento da capacidade gerencial dos níveis central, regional, municipal e escolar (RAMOS; LIRA; SOARES, 2012).

No governo de Lúcio Alcântara (2003-2006) (PSDB-CE) ocorreu a sistematização da GpR, que foi adotada explicitamente em 2003, mas somente foi anunciada oficialmente em 2006, em mensagem do governo do estado à Assembleia Legislativa. De acordo com Camarão, Ramos e Albuquerque (2015), "a Gestão por Resultados teria como 'pressuposto fundamental' a ideia de que 'avanços econômicos e sociais são complementares', eles 'ou avançam juntos ou retrocedem juntos'" (p. 382).

Ao ser eleito em 2006, Cid Gomes, do Partido Socialista Brasileiro (PSB), deu continuidade às medidas adotadas nos governos anteriores, com $\mathrm{O}$ objetivo de "reforçar alguns setores voltados para o mercado internacional, bem como conservar o apreço pelo forte controle das contas públicas" (NOBRE, 2008, p. 81).

De acordo com os estudos de Carvalho (2008a, 2008b), este governo é considerado como o terceiro período das reformas gerenciais do Estado e da educação no Ceará, correspondendo ao ciclo dos Ferreira Gomes. O início desse novo ciclo não representou um rompimento político com o governo de Tasso Jereissati, ocorrendo a manutenção e o aprimoramento das concepções empresariais de gestão (CAMARÃO; RAMOS; ALBUQUERQUE, 2015).

Durante a gestão de Cid Gomes ${ }^{4}$ (PSB) foram utilizadas estratégias voltadas à formação gerencial dos gestores públicos e escolares (VALDEVINO, 2018). Nesse período, destaca-se a relação estabelecida entre o governo estadual e o Banco Mundial por meio da assinatura de um novo acordo de cooperação internacional, o Projeto de Apoio à Inclusão Social e Crescimento Econômico, ou SWAP II, que teve início no governo de Lúcio Alcântara, com vigência de 19 de março de 2009 até 30 de junho de 2012. O Projeto tinha

\footnotetext{
${ }_{4}^{4}$ Ressalta-se que em 2013, segundo mandato de Cid Gomes, o governador se filiou ao Partido Republicano da Ordem Social (PROS).
} 
como objetivo o fortalecimento do sistema de gestão por resultados do Estado e a promoção da melhoria na qualidade dos serviços de educação e de saúde. O Banco Mundial, ao conceder o empréstimo, previa o cumprimento de metas e a elaboração de planos estratégicos (RAMOS et al., 2018).

A instituição de políticas de accountability na educação cearense ocorreu, a partir de 2007, quando os resultados do sistema de avaliação externa, o Spaece, passaram a ser utilizados como parâmetro para a premiação de escolas municipais e municípios. A partir de então, o governo do estado do Ceará implanta uma proposta de "regime de colaboração" em que assume o papel de avaliador da educação oferecida pelas redes municipais de ensino, instituindo medidas de regulação da educação municipal, com a criação de políticas de bonificação por resultados.

\section{Iniciativas de accountability na educação cearense}

Na educação pública cearense, a implantação da GpR articula as

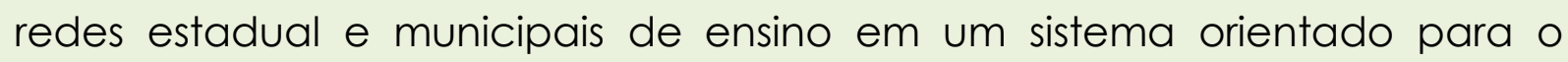
alcance de metas, que conduziu à instituição de políticas de accountability.

A seguir, são apresentadas as políticas de accountability adotadas no estado do Ceará: 1. criação do Spaece; 2. instituição do Paic; 3. reformulação dos critérios para a distribuição do ICMS; e 4. instituição de premiações de âmbito estadual com base nos resultados do Spaece, Prêmio Escola Nota Dez, Prêmio Aprender pra Valer e Prêmio Foco na Aprendizagem.

\section{Sistema Permanente de Avaliação da Educação Básica do Ceará (Spaece)}

Em 1992 foi institucionalizado o Sistema de Avaliação do Rendimento Escolar em âmbito estadual. Nesse período, a avaliação foi destinada aos alunos das escolas da rede estadual. Os três primeiros anos do Sistema consistiram na fase de expansão da avaliação para todas as escolas estaduais urbanas. Dantas (2015) afirma que a primeira edição da avaliação contemplou somente a capital, Fortaleza, quando foram avaliados alunos da $4^{a}$ a $8^{a}$ séries de 157 escolas estaduais. 
Dantas (2015) observa que no ano de 2000, por meio da Portaria n. 101/2000, o sistema passou a ser denominado oficialmente Sistema Permanente de Avaliação da Educação Básica do Ceará (Spaece). No mesmo ano estava prevista a realização da sexta edição da avaliação, que não ocorreu em decorrência de problemas burocráticos e de operacionalização. No ano seguinte, 2001, foi concebido o SpaeceNet, associado ao Programa Internet na Escola.

Em 2002 foi instituído o Prêmio Educacional "Escola do Novo Milênio Educação Básica de Qualidade no Ceará", pela Lei n. 13.203, de 21 de fevereiro de 2002, que associou os resultados do Spaece 5 à premiação dos servidores, concedida apenas uma vez no ano de 2002. O pagamento do Prêmio era destinado às escolas da rede estadual e tinha como critério para sua concessão a adesão, por parte da escola, ao "Projeto de Melhoria da Escola".

A partir de 2003, o Spaece contemplou todos os municípios do Ceará. A amostra das escolas estaduais foi de 28.557 alunos da $8^{a}$ série do ensino fundamental e da $3^{a}$ série do Ensino Médio. Em 2004, passou a contemplar também as escolas integrantes das redes municipais de ensino. Nesse ano, foi universalizada a participação das escolas da rede estadual e municipal que possuíam mais de 25 alunos nas turmas avaliadas. Nos anos de 2004 e 2006, foi utilizado como parâmetro a escala de desempenho do Saeb. Nesse período, a Fundação Cesgranriob foi a responsável pela organização do Spaece. As avaliações tinham como público-alvo os alunos das séries $5^{\circ}$ e $9^{\circ}$ anos do ensino fundamental e do $3^{\circ}$ ano do ensino médio (DANTAS, 2015).

O Spaece, no ano de 2007, foi reformulado e sua aplicação passou a ser anual. Até então, a aplicação era bianual. As avaliações que compõem o sistema são realizadas por meio de testes de desempenho dos estudantes

\footnotetext{
5 Baseada nos resultados do SpaeceNet de 2001 das turmas de $8^{a}$ série e $3^{\circ}$ ano do ensino médio.

6 A Fundação Cesgranrio é uma entidade de direito privado, de natureza educacional, cultural e assistencial, e que não tem fins lucrativos. Tem como principais atividades: concursos públicos, vestibulares, capacitação de professores, pesquisa, certificação e projetos sociais e culturais no Brasil (CESGRANRIO, 2020).
} 
nas disciplinas de Língua Portuguesa e Matemática e de questionários contextuais para coleta de dados sobre as escolas e os alunos. Abrangem as escolas públicas das redes estadual e municipais, avaliando os alunos da Educação Básica, desde as etapas de alfabetização até o ensino médio7 (CAEd, 2020).

Para a análise dos resultados nas avaliações que compõem o Spaece são considerados os padrões de desempenho, que são relacionados ao nível de proficiência dos estudantes (CAEd, 2020). Para cada série são utilizados padrões de desempenho diferentes e relacionados ao valor da proficiência que se divide em níveis.

Desde 2008, a Seduc/CE, em parceria com o Centro de Políticas Públicas e Avaliação da Educação da Universidade Federal de Juiz de Fora (CAEd/UFJF), coordena o Spaece, inclusive com a aplicação do Spaece-Alfa. Criado em 2007, o Spaece-Alfa destina-se aos alunos do $2^{\circ}$ ano, com o objetivo de identificar e analisar seus níveis de proficiência de leitura. Essa avaliação surgiv em decorrência do Paic.

É através do desempenho dos alunos nas avaliações do Spaece que se constitui uma rede de ranqueamento de escolas públicas das redes estadual e municipais. Seus resultados são utilizados como referência para o pagamento de incentivos monetários às escolas, docentes e discentes por meio de premiações, consistindo no parâmetro mais importante para as políticas de responsabilização e prestação de contas no estado. De acordo com Afonso (2009a), a avaliação externa é a porta de entrada para as políticas de accountability, consiste em um instrumento central da regulação da educação, por meio da criação de parâmetros e indicadores de qualidade para o monitoramento das políticas educacionais.

\section{Programa de Alfabetização na Idade Certa (Paic)}

\footnotetext{
7 Em 2008, foram inseridas as três séries do ensino médio e, em 2015, as séries finais da Educação de Jovens e Adultos (EJA) presencial. As turmas dessa modalidade participaram de forma amostral até o ano de 2014. A aplicação da prova ocorre de forma censitária a partir de 2015, em que participam as turmas do primeiro período e anos finais da rede estadual (CAEd, 2020).
} 
O Paic, segundo o governo do estado, consiste em uma política de cooperação entre o governo do estado e os municípios, em parceria com o Fundo das Nações Unidas para a Infância (Unicef) e instituições da sociedade civil, com apoio do governo federal, cujo objetivo é alfabetizar todos os alunos das redes públicas de ensino do estado até os sete anos de idade (CEARÁ, 2012). Teve origem no Comitê Cearense para Eliminação do Analfabetismo Escolar (CCEAE), instituído pela Assembleia Legislativa em 2004. Constituído pelo Fundo Internacional de Emergência das Nações Unidas para a Infância (UNICEF), a Seduc/CE e as universidades públicas do estado do Ceará, esse comitê tinha como objetivo realizar um diagnóstico da condição de leitura e escrita de crianças que estavam cursando a $3^{a}$ série, hoje $2^{\circ}$ ano, da rede pública de 48 municípios cearenses. Os resultados desse estudo evidenciaram que o fracasso da etapa inicial do ensino fundamental já se anunciava no fracasso do processo de alfabetização dos anos iniciais. De acordo com Coelho (2013), a experiência da política educacional implantada no município de Sobral/CE, que estabeleceu a meta de garantir a alfabetização de todas as crianças de seis e sete anos, consistiu em inspiração para a criação do Paic na educação estadual.

A implementação do Paic, segundo o governo do estado, está situada no marco do regime de colaboração8, previsto na Constituição Federal de 1988. A partir desse programa foi acordado entre o governo do estado e municípios cearenses a colaboração por meio da: 1. formação, elaboração e distribuição de material e acompanhamento pedagógico; 2. monitoramento; e 3. avaliação e incentivos financeiros ligados a resultados de aprendizagem. Foi transformado em uma política pública prioritária do governo estadual em 2007, por meio da Lei n. ${ }^{0}$ 14.026, de 17 de dezembro de 2007, que prevê que, em cumprimento ao regime de colaboração, que o estado prestará cooperação técnica e financeira aos municípios cearenses, com vistas à melhoria dos resultados de aprendizagem. A lei previu,

\footnotetext{
${ }^{8}$ A Constituição Federal de 1988 prevê, em seu artigo 2011, que a União, os Estados, o Distrito Federal e os Municípios, na organização de seus sistemas de ensino, devem definir formas de colaboração, de modo a assegurar a universalização do ensino obrigatório (BRASIL, 1988).
} 
inicialmente, a garantia da aquisição, por todas as crianças de sete anos, das competências de leitura e escrita esperadas nessa idade. Essa faixa etária corresponde a ações de forma direta para o $2^{\circ}$ ano do ensino fundamental (CEARÁ, 2007a).

No ano de 2011, O Paic foi expandido para $\circ 5^{\circ}$ ano do ensino fundamental e, em 2015, foi lançado o Mais Paic. Essa mudança teve como finalidade ampliar o trabalho de cooperação já existente com os 184 municípios que, além da Educação Infantil e do $1^{\circ}$ ao $5^{\circ}$ ano, passou a contemplar turmas do $6^{\circ}$ ao $9^{\circ}$ ano do ensino fundamental das escolas públicas cearenses (CAEd, 2020).

O Paic está organizado em cinco eixos: gestão da educação municipal; avaliação externa; alfabetização; formação do leitor; e educação infantil. Nesse pacto, a Seduc/CE é responsável pela assessoria técnica e por realizar a avaliação dos resultados dos alunos do $2^{\circ}, 5^{\circ}$ e $9^{\circ}$ anos do ensino fundamental. Aos municípios cabe disponibilizar as equipes técnicas para a implementação das ações propostas e fornecer o apoio logístico e materiais necessários às atividades relacionadas ao Paic (CEARÁ, 2012).

Nesse contexto, Coelho (2013) afirma que os resultados do Spaece Alfa, que é um dos indicadores do Paic, mostram a evolução dessas políticas por meio da taxa de participação dos municípios que cresceu entre 2007 e 2011. Para a autora, esse dado é um indicador tanto de eficiência quanto da presença efetiva do aluno na escola como uma tarefa de responsabilidade por parte das instituições de ensino com os estudantes. "Além disso, é sinal da melhoria dos processos de gestão das secretarias municipais na medida em que o crescimento se deu no âmbito das redes, e não somente de algumas escolas" (COELHO, 2013, p. 27).

É nessa lógica que o Paic, de um programa especial para a erradicação do analfabetismo escolar, converteu-se num modelo oficial de gestão por resultados com base numa política de responsabilização. Ele é apresentado pelo governo do estado como a principal ação que desencadeia resultados positivos no Índice de Desenvolvimento da Educação Básica (Ideb) (RAMOS et al., 2018). 
De acordo com Camarão, Ramos e Albuquerque (2015), o Paic consolidou a política de GpR como importante, senão principal, vertente das políticas educacionais, que envolveu e integrou esferas de governo, instituição escolar, docentes e discentes na corrida pelos resultados. De acordo com os autores, isso ocorre porque a elevação dos resultados consiste no principal foco do programa, que tem no Spaece o seu grande instrumento avaliativo externo. Mediante a consolidação do Spaece, no âmbito do Paic, a GpR e as políticas de accountability se estabeleceram na política educacional cearense.

\section{Reformulação nos Critérios para a Distribuição do ICMS}

Outro mecanismo adotado pelo governo estadual que está relacionado à GpR, e que instituiu iniciativa de accountability na educação do Ceará, consistiu no estabelecimento de novos critérios para o rateio do ICMS9, por meio da aprovação da Lei Estadual n. ${ }^{\circ}$ 14.023, de 17 de dezembro de 2007. O valor do repasse do imposto aos municípios passou a ser vinculado aos resultados obtidos nas áreas de Educação, Saúde e Meio Ambiente. Dos $25 \%$ da cota-parte dos municípios do ICMS, $18 \%$ estão vinculados aos resultados de rendimento e desempenho dos estudantes da educação básica. A Lei previa que o Índice Municipal de Qualidade (IQE) de cada município deveria ser formado pela taxa de aprovação dos alunos do $1^{\circ}$ ao $5^{\circ}$ ano do ensino fundamental e pela média obtida pelos alunos do $2^{\circ}$ e $5^{\circ}$ ano da rede municipal em avaliações de aprendizagem (CEARÁ, 2007b, art. $2^{\circ}$ ). $O$ IQE é calculado considerando os resultados do desempenho dos alunos do $2^{\circ}$ e $5^{\circ}$ anos no spaece.

Em 2015, com a aprovação da Lei n. ${ }^{0}$ 15.922, de 15 de dezembro, foi alterado o segundo artigo da Lei n. ${ }^{\circ}$ 14.023, de 17 de dezembro de 2007. A partir de então, foi estabelecido que o índice deve considerar a taxa de

\footnotetext{
9 Os critérios para distribuição da parcela de $25 \%$ oriunda do ICMS para os municípios foi prevista inicialmente na Lei $n^{\circ} 12.612$, de 07 de agosto de 1996, no governo de Tasso Jereissati. A Lei previa que o repasse de $12,5 \%$ dessa parcela era relativo aos gastos em educação sobre a receita do município.
} 
aprovação dos alunos do ensino fundamental e a média obtida em avaliações de aprendizagem, passando a incluir também o $9^{\circ}$ ano, além do $2^{\circ}$ e $5^{\circ}$ anos. De acordo com a Lei n. ${ }^{\circ} 17.130$, de 12 de dezembro de 2019, os repasses efetuados aos municípios devem considerar os índices aferidos pelo Instituto de Pesquisa e Estratégia Econômica do Ceará (IPECE).

A mudança na distribuição do ICMS, considerando os resultados em Educação, Saúde e Meio Ambiente, segundo Dantas (2015), teve por objetivo premiar os municípios que se destacam nessas áreas. Desse modo, desde então, àqueles que alcançam melhores resultados recebem maior repasse da cota-parte do ICMS. O autor destaca que essa iniciativa consistiu na maneira que o governo estadual encontrou de incentivar a participação dos envolvidos no cumprimento de metas e demonstrar a importância desse modelo avaliativo na constituição de sua agenda, movendo municípios, cidades, escolas e professores em torno dos alunos e da qualidade da educação oferecida.

Sobre tal medida, Costa (2020, p. 109) afirma que através do rateio da cota-parte do ICMS entre os municípios, calculado pela taxa de aprovação e proficiência em avaliação de larga escala, "o estado estimula uma corrida de obstáculos entre redes municipais distintas em tamanho, problemas e características". Isso ocorre porque, de acordo com o autor, o estado coloca sob os mesmos critérios redes que variam de números de escolas e matrículas, e como não há dinheiro novo, os municípios que avançam seus resultados e aumentam seu IQE são premiados com recursos daqueles que não conseguiram melhorar ou aumentar o índice.

Costa (2020, p. 111 ) aponta que,

[...] ao estabelecer os mesmos critérios para todos os municípios, independente da complexidade e tamanho das redes escolares, criou-se uma 'competição desigual' entre os municípios, gerando situações de iniquidade entre eles. 
Desse modo, reforçam-se as desigualdades existentes entre os municípios e suas redes de ensino, sob um discurso de valorização do mérito e do esforço dos profissionais e estudantes envolvidos.

\section{Iniciativas de Premiação de Escolas, Alunos e Profissionais da Educação}

No estado do Ceará, os resultados das avaliações externas das escolas públicas gerados pelo Spaece são utilizados para a premiação de alunos, profissionais da educação e escolas. Em 2009, foi instituída a Lei n. ${ }^{\circ} 14.483$, de 8 de outubro de 2009, que prevê a premiação dos alunos do ensino médio com melhor desempenho acadêmico nas escolas da rede pública do estado. De acordo com o art. $1^{\circ}$ dessa lei, os alunos das três séries do ensino médio das escolas da rede estadual de ensino do Ceará serão premiados com um notebook, conforme o seu desempenho nas provas anuais do Spaece ou do Enem. Para receber o prêmio, os alunos do $1^{\circ}$ ano do ensino médio deveriam alcançar as médias de proficiência nas provas de Língua Portuguesa e Matemática do Spaece. Os alunos do $2^{\circ}$ e do $3^{\circ}$ ano precisavam alcançar as médias do Spaece ou a média geral das provas do ENEM, pontuação igual ou superior a 520 pontos para o $2^{\circ}$ ano e 560 pontos para o $3^{\circ}$ (CEARÁ, 2009b).

Nesse mesmo ano, foi instituído para o ensino médio o "Prêmio Aprender pra Valer", por meio da Lei n. ${ }^{\circ} 14.484$, de 08 de outubro de 2009. Um dos objetivos do prêmio consistiu em reconhecer o mérito das escolas que tivessem alcançado as metas anuais de evolução da aprendizagem dos alunos do Spaece e dar visibilidade às instituições que tiveram experiências exitosas e passíveis de replicabilidade em outras escolas da rede estadual. A iniciativa concede premiação ao quadro funcional de todas as escolas que alcançarem as metas anuais de evolução da aprendizagem dos alunos do ensino médio, tendo por base os resultados do Spaece (CEARÁ, 2009C). Em 2017, esse Prêmio foi substituído pelo Programa "Foco na Aprendizagem", que realiza o pagamento do $14^{\circ}$ salário para as escolas da rede estadual com as maiores médias nos resultados do Spaece.

O Programa "Foco na Aprendizagem" foi instituído pela Lei n. ${ }^{0}$ 16.448, de 12 de dezembro de 2017, que definiu a concessão anual de premiação 
pecuniária aos integrantes do quadro funcional de até 50 escolas de ensino médio da rede estadual de ensino do Ceará, com base no desempenho obtido no Spaece (CEARÁ, 2017). Um de seus objetivos consiste em mobilizar os gestores, professores, servidores e demais colaboradores da escola na implementação coletiva de um projeto pedagógico com foco na permanência e na aprendizagem dos estudantes, para que todos concluam o ensino médio com qualidade.

Para o ensino fundamental, outro mecanismo de indução à melhoria dos resultados nas avaliações externas consiste na criação do "Prêmio Escola Nota Dez", Lei n. ${ }^{14.371}$, de 19 de junho de 2009, com o objetivo de premiar as escolas públicas com o melhor resultado no Índice de Desempenho Escolar - Alfabetização (IDE-ALFA) ${ }^{10}$. Essa Lei foi revogada posteriormente, sendo substituída pela Lei Estadual n. ${ }^{\circ}$ 15.052, de 6 de dezembro de 2011 , que passou a incluir os resultados do Índice de Desempenho Escolar - $5^{\circ}$ ano (IDE-5). Em 2015, o Prêmio foi modificado novamente, com a aprovação da Lei n. ${ }^{\circ} 15.923$, de 15 de dezembro de 2015, que definiu a concessão da premiação também às escolas públicas que tivessem obtido os melhores resultados de aprendizagem, expressos, além do IDE ALFA e IDE-5, no Índice de Desempenho Escolar - $9^{\circ}$ ano (IDE-9) (CEARÁ, 2015).

O cálculo do valor da premiação considera a renda per capita por aluno. Para as escolas que têm o melhor desempenho, o valor concedido é de $R \$ 2.000,00$ (dois mil reais), de acordo com o número de alunos avaliados. Para as escolas com baixo desempenho, o valor é de $R \$ 1.000,00$ (um mil reais) por discente. Parte do valor repassado, $25 \%$, pode ser destinado para bonificar os profissionais da escola (AUGUSTO, 2019). De acordo com estudo realizado por Corrêa (2018), a maioria das escolas opta por dividir esses recursos somente entre os integrantes da equipe pedagógica e entre os professores das séries premiadas.

Para o recebimento do Prêmio, as instituições premiadas com os melhores resultados, chamadas de escolas apoiadoras, devem realizar um

\footnotetext{
10 Correspondente aos resultados dos alunos do $2^{\circ}$ ano do ensino fundamental avaliados no Spaece Alfa.
} 
trabalho junto às instituições que tiveram os menores índices, denominadas de escolas apoiadas. O pagamento do valor é feito em duas parcelas. As escolas apoiadoras recebem a primeira parcela a que cada unidade tem direito, equivalente a $75 \%$ do valor total, mediante aprovação pela Seduc/CE de um plano de aplicação de recursos financeiros e das ações a serem realizadas na escola apoiada. O restante é quitado após a escola comprovar a execução da ação com as escolas que tenham obtido os menores resultados, o que inclui a elevação das médias do Spaece das escolas apoiadas (CEARÁ, 2019).

As escolas apoiadas recebem, inicialmente, $50 \%$ do valor do Prêmio. A segunda parcela somente será concedida com o cumprimento da condição de elevação dos resultados de seus estudantes no Spaece. Desde 2015, não foram mais considerados os resultados do $2^{\circ}$ ano do ensino fundamental para - repasse às escolas com menores índices, porque, de acordo com representante da Seduc/CE (apud CORREA, 2018, p. 123), "as instituições já teriam alcançado um nível alto de alfabetização, previsto na lei que regulamenta o Prêmio Escola Nota Dez". Desse modo, são consideradas como principal critério para esse pagamento, somente as escolas com os menores índices nas turmas do $5^{\circ}$ e $9^{\circ}$ anos do ensino fundamental (CORREA, 2018). É importante ressaltar que, para o recebimento do Prêmio, as escolas precisam garantir a participação de $90 \%$ dos alunos no momento das provas, além de atingir as médias que são determinadas pelo estado para cada série (AUGUSTO, 2019).

A entrega do Prêmio Escola Nota Dez é realizada em um momento solene, organizado pela Seduc/CE, que se materializa na entrega de troféus às escolas. Esse evento costuma contar com a participação do governador, secretária de educação, prefeitos, representantes das escolas, entre outros, que se reúnem na capital do estado, Fortaleza. A solenidade é sucedida de outros eventos nas próprias cidades (CORREA, 2018).

O Prêmio, inicialmente, segundo Corrêa (2018), tinha por objetivo exercer uma função indutora sobre os professores, visando cumprir os objetivos do Paic de melhorar a aprendizagem dos alunos. Foram incorporados alterações e incrementos que visaram à disseminação de práticas 
pedagógicas exitosas e de gestão das escolas compreendidas como adequadas pela Seduc/CE. Um dos indicadores utilizados pela secretaria para realizar o cálculo das médias desse Prêmio é o mesmo componente utilizado para o repasse da cota-parte do ICMS.

Nesse contexto, as redes municipais passaram, cada vez mais, a ser cobradas pela elevação dos resultados e o Prêmio Escola Nota Dez tornou-se uma política estadual que distribui recursos diretos para as escolas públicas municipais, cujo o objetivo é favorecer a competitividade entre as escolas para que alcancem os melhores resultados e os seus municípios ascendam na escala do ranqueamento. Contudo, Correa (2018, p. 195) chama atenção para o fato de que "a forma como a política é desenhada pode diferir, em muitos aspectos, da forma como essa política chega à ponta, e é implementada pelos atores escolares".

Segundo Correa (2018), com a exposição pública dos resultados, ocorre um efeito de constrangimento das escolas que obtém os mais baixos índices do estado e ficam na posição de apoiadas. Diante dessa exposição e da pressão das secretarias municipais de educação pela melhoria dos resultados, os professores passam a se dedicar cada vez mais para o cumprimento das metas, enfatizando o desenvolvimento das atividades voltadas às avaliações externas.

\section{CONSIDERAÇÕES FINAIS}

O modelo gerencial de administração pública propugnou a descentralização, que na educação se efetiva principalmente com a municipalização do ensino. Nessa política, a educação municipal é interligada de forma subordina às diretrizes do governo do estado, constituindo o que Freitas (2007) denomina como um regime de colaboração "sob condicionalidades". Nesse regime, os municípios aderem às políticas estaduais em troca de apoio técnico e financeiro, mas sem deterem o poder de negociação dos termos da colaboração, da definição das medidas a serem adotadas e sem assegurar o fortalecimento de sua autonomia diante das demandas da realidade local. Ao mesmo tempo, esse modelo de 
administração pública adotado propiciou, de acordo com Freitas (2007, p. 192), "um aumento do poder de regulação do Estado central, na medida que as práticas descentralizadas, processos de flexibilização e contabilização de desempenhos foram submetidos a um maior controle centralizado".

Tal situação é observada na educação cearense, em que o governo do estado assumiu funções relativas à regulação e ao controle da educação municipal, mediados por processos centralizados de avaliação externa, de monitoramento do desempenho de estudantes, de divulgação de resultados e da concessão de premiação.

A GpR favorece a disseminação das políticas de accountability, implantadas no âmbito estadual desde 2007. Na educação, elas se consolidam por meio do Spaece, Prêmio Escola Nota Dez, Programa Foco na Aprendizagem, Paic e os repasses referentes à cota-parte do ICMS. Essas iniciativas têm a avaliação externa como um instrumento central de regulação. Em uma perspectiva gerencialista, a lógica presente nos documentos se aproxima do conceito de qualidade da empresa privada, que tem entre os seus principais objetivos a máxima produção e o mínimo de custo. Esses indícios apontam que a instituição dessas iniciativas favoreceu a competividade entre os profissionais da educação e municípios.

Oliveira e Clementino (2019) consideram que o estado do Ceará adota políticas de alta responsabilização no setor educacional, caracterizadas como high stakes, de alto risco. Tais políticas geram implicações morais e materiais, na medida em que contemplam o estabelecimento de sanções e de recompensas, pela concessão de premiação para professores, demais profissionais da educação e estudantes pelos resultados alcançados nas avaliações externas.

A articulação entre avaliação externa, prestação de contas e responsabilização visa condicionar os docentes para o cumprimento de metas, o que põe em debate o pagamento da bonificação como forma de valorizar os profissionais do magistério. Nesse sentido, é necessário aprofundar os estudos sobre o tema, pois, de acordo com Oliveira e Clementino (2019), os resultados de sistemas próprios de avaliação, como forma de responsabilizar 
os docentes, acabam por traduzir-se em uma visão restrita do processo educacional.

\section{REFERÊNCIAS}

AFONSO, A. J. Nem tudo o que conta em educação é mensurável ou comparável. Crítica à accountability baseada em testes estandardizados e rankings escolares. Revista Lusófona de Educação, Lisboa, v. 13, n. 13, p. 1329, jul. 2009a. Disponível em: http://hdl.handle.net/10437/1753. Acesso em: 29 abr. 2020.

AFONSO, A. J. Avaliação educacional: regulação e emancipação. 4. ed. São Paulo: Cortez, 2009b.

AFONSO, A. J. Estado, políticas educacionais e obsessão avaliativa.

Contrapontos, Itajaí, v. 7, n. 1. p. 11-22, jan./abr. 2007. Disponível em: https://siaiap32.univali.br/seer/index.php/rc/article/view/888/741. Acesso em: 29 abr. 2020.

AGUIAR, R. R. O Regime de colaboração do Ceará. Em Aberto, Brasília, v. 19, n. 75, p. 133-137, jul. 2002. DOl: https://doi.org/10.24109/2176-

6673.emaberto.19i75.2173. Disponível em:

http://rbep.inep.gov.br/ojs3/index.php/emaberto/article/view/2576. Acesso em: 01 nov. 2019.

AUGUSTO, F. Com os melhores resultados na história, 182 municípios recebem Prêmio Escola Nota Dez. Secretaria da Educação - SEDUC [Portal]. Fortaleza, 6 jun. 2019. Disponível em: https://www.seduc.ce.gov.br/2019/06/06/com-osmelhores-resultados-na-historia-182-municipios-recebem-premio-escola-notadez/. Acesso em: 29 abr. 2020.

BARBALHO, A. Os modernos e os tradicionais: cultura política no Ceará contemporâneo. Estudos de Sociologia, Araraquara/SP, v. 12, n. 22, p. 27-42, 2007. Disponível em:

http://bibliotecadigital.tse.jus.br/xmlui/handle/bdtse/3983. Acesso em: 16 jan. 2021.

BONAMINO, A.; SOUSA, S. Z. Três gerações de avaliação da educação básica no Brasil: interfaces com o currículo da/na escola. Educação e Pesquisa, São Paulo, v. 38, n. 2, p. 373-388, abr./jun. 2012. DOl: https://doi.org/10.1590/S1517-97022012005000006. Disponível em: http://www.scielo.br/pdf/ep/v38n2/aopep633.pdf. Acesso em: 29 abr. 2020.

BRASIL. [Constituição (1988)]. Constituição da República Federativa do Brasil. Diário Oficial da União, Brasília. 1988. Disponível em: https://www.planalto.gov.br/ccivil_03/Constituicao/Constituicao.htm. 
Acesso em: 10 jan. 2020.

CAMARÃO, V. C.; RAMOS, J. F. P.; ALBURQUERQUE, F. C. A. Política da gestão por resultados na educação cearense (1995-2014). Praia Vermelha, Rio de Janeiro, v. 25, n. 2, p. 299-484, jul./dez. 2015. Disponível em:

https://revistas.ufrj.br/index.php/praiavermelha/article/view/10160. Acesso em: 29 abr. 2020.

CARVALHO, R. V. A. Ciclos Políticos: reflexões teóricas e apontamentos empíricos sobre condições de longevidade políticas em esferas públicas midiatizadas. In: Encontro Anual da ANPOCS, 32, 2008, Caxambu, MG, Anais [...]. Caxambu: ANPOCS, 2008a. Disponível em:

http://opiniaopublica.ufmg.br/site/files/biblioteca/Rejane-Maria-

Vasconcelos-Accioly-Carvalho.pdf. Acesso em: 12 ago. 2021.

CARVALHO, R. V. A. Fronteiras simbólicas borradas na transição de ciclos políticos: A campanha para o governo do Ceará em 2006. Revista de Ciências Sociais, Fortaleza, v. 39, n. 2, p. 22-43, 2008b.

CEARÁ. Lei n. 12.452, de 6 de junho de 1995. Dispõe sobre o Processo de Municipalização do Ensino Público do Ceará e dá outras providências. Fortaleza: Assembleia Legislativa do Estado do Ceará, 1995. Disponível em: https://belt.al.ce.gov.br/index.php/legislacao-do-ceara/organizacaotematica/trabalho-administracao-e-servico-publico/item/2401-lei-n-12-452de-06-06-95-d-o-de-27-06-95. Acesso em: 09 ago. 2021.

CEARÁ. Lei n. 13. 203 de 21 de fevereiro de 2002. Institui o Prêmio Educacional "Escola do Novo Milênio - Educação Básica de Qualidade no Ceará", relativo ao ano de 2001 e dá outras providências. Fortaleza: Assembleia Legislativa do Estado do Ceará, 2002. Disponível em: https://belt.al.ce.gov.br/index.php/legislacao-do-ceara/organizacaotematica/educacao/item/3422-lei-revogada-pela-lei-n-13-541-de-22-11-04lei-n-13-203-de-21-02-02-do-25-02-02.

Acesso em: 11 ago. 2021.

CEARÁ. Lei n. ${ }^{\circ}$ 14.026, de 17 de dezembro de 2007. Cria o Programa Alfabetização na Idade Certa (PAIC), de cooperação técnica e incentivo para melhoria dos indicadores de aprendizagem nos municípios cearenses e dá outras providências. Fortaleza: Assembleia Legislativa do Estado do Ceará, [2007a]. Disponível em:

https://paic.seduc.ce.gov.br/images/leis/lei_14026_2007.pdf. Acesso em: 11 mar. 2020.

CEARÁ. Lei $\mathbf{n} .^{\circ}$ 14.023, de 17 de dezembro de 2007. Modifica dispositivos da Lei n. ${ }^{\circ} 12.612$, de 7 de agosto de 1996, que define critérios para distribuição da parcela de receita do produto e arrecadação do Imposto Sobre Operações Relativas à Circulação de Mercadorias e sobre Prestações de 
Serviços de Transporte Interestadual e Intermunicipal e de Comunicação ICMS, pertencente aos municípios e dá outras providências. Fortaleza: Assembleia Legislativa do Estado do Ceará, [2007b]. Disponível em: http://pesquisa.doe.seplag.ce.gov.br/doepesquisa/sead.do?page=pesquisa Avancada\&cmd=10\&action. Acesso em: 27 abr. 2020.

CEARÁ. Lei $\mathbf{n} .^{\circ}$ 14.371, de 19 de junho de 2009. Cria o Prêmio Escola Nota Dez, destinado a premiar as escolas públicas com melhor resultado no Índice de Desempenho Escolar - Alfabetização (IDEALFA), e dá outras providências. Fortaleza: Assembleia Legislativa do Estado do Ceará, [2009a]. Disponível em: https://belt.al.ce.gov.br/index.php/legislacao-do-ceara/organizacaotematica/educacao/item/5365-lei-n-14-371-de-19-06-09-d-o-de-19-06-09revogado-pela-lei-n-15-923-de-15-12-15? tmpl=component\&print=1. Acesso em: 10 ago. 2021.

CEARÁ. Lei n. ${ }^{\circ}$ 14.483, de 08 outubro de 2009. Institui a premiação para alunos do ensino médio com melhor desempenho acadêmico nas escolas da rede pública de ensino do estado e dá outras providências. Fortaleza: Assembleia Legislativa do Estado do Ceará, [2009b]. Disponível em:

https://belt.al.ce.gov.br/index.php/legislacao-do-ceara/organizacaotematica/educacao/item/4994-lei-n-14-483-de-08-10-09-d-o-de-20-10-09. Acesso em: 01 mar. 2020.

CEARÁ. Lei n. ${ }^{\circ}$ 14.484, de 08 de outubro de 2009. Institui o Prêmio Aprender pra Valer, destinado ao quadro funcional das escolas da rede estadual de ensino, e dá outras providências. Fortaleza: Assembleia Legislativa do Estado do Ceará, [2009c]. Disponível em:

https://belt.al.ce.gov.br/index.php/legislacao-do-ceara/organizacaotematica/educacao/item/4993-lei-14-484-de-08-10-09-d-o-de-20-10-09. Acesso em: 01 mar. 2020.

CEARÁ. Lei n 15.052, de 06 de dezembro de 2011. Institui o Prêmio Escola Nota Dez, destinado a premiar as escolas públicas com melhores resultados de aprendizagem no segundo e quinto anos do ensino fundamental, e dá outras providências. Fortaleza: Assembleia Legislativa do Estado do Ceará, 2011 . Disponível em: https://belt.al.ce.gov.br/index.php/legislacao-doceara/organizacao-tematica/educacao/item/2792-lei-n-15-052-de-06-12-11do-12-12-11-revogado-pela-lei-n-15-923-de-15-1215 ? tmpl=component\&print=1. Acesso em: 11 mar. 2020.

CEARÁ. Lei $\mathbf{n} .^{\circ} \mathbf{1 5 . 9 2 2}$, de 15 de dezembro de 2015. Altera a redação do Inciso II do Art. $1^{\circ}$ da Lei $n^{\circ} 12.612$, de 7 de agosto de 1996. Fortaleza: Assembleia Legislativa do Estado do Ceará, [2015a]. Disponível em: https://belt.al.ce.gov.br/index.php/legislacao-do-ceara/organizacaotematica/educacao/item/4226-lei-n-15-922-de-15-12-15-d-o-15-1215 ? tmpl=component\&print=1. Acesso em: 08 ago. 2021. 
CEARÁ. Lei n. $^{\circ}$ 15.923, de 15 de dezembro de 2015. Institui o prêmio escola nota dez, destinado a premiar as escolas públicas com melhores resultados de aprendizagem no segundo, quinto e nono anos do ensino fundamental. Fortaleza: Assembleia Legislativa do Estado do Ceará, [2015b]. Disponível em: https://belt.al.ce.gov.br/index.php/legislacao-do-ceara/organizacaotematica/educacao/item/4227-lei-n-15-923-de-15-12-15-d-o-15-12-15. Acesso em: 01 mar. 2020.

CEARÁ. Lei $\mathbf{n} .^{\circ} \mathbf{1 6 . 4 4 8}$, de 12 de dezembro de 2017. Institui o prêmio foco na aprendizagem, destinado ao quadro funcional das escolas da rede estadual de ensino. Fortaleza: Assembleia Legislativa do Estado do Ceará, [2017]. Disponível em: https://belt.al.ce.gov.br/index.php/legislacao-doceara/organizacao-tematica/educacao/item/6057-lei-n-16-448-de-12-12-17d-o-12-12-17. Acesso em: 01 mar. 2020.

CEARÁ. Lei n. ${ }^{\circ}$ 17.130, de 12 de dezembro de 2019. Altera a redação do Art. $2^{\circ}$ da Lei $n^{\circ} 15.922$, de 15 de dezembro de 2015. Fortaleza: Assembleia Legislativa do Estado do Ceará, 2019. Disponível em:

https://belt.al.ce.gov.br/index.php/legislacao-do-ceara/organizacaotematica/educacao/item/6914-lei-n-17-130-12-12-19-d-o-16-12-19. Acesso em: 12 ago. 2021.

CEARÁ. Secretaria da Educação. Regime de colaboração para a garantia do direito à aprendizagem: o Programa Alfabetização na Idade Certa (PAIC) no Ceará / Secretaria da Educação. Fundo das Nações Unidas para a Infância (UNICEF). Fortaleza: SEDUC, 2012. 196 p.

CENTRO DE POLÍTICAS PÚBLICAS E AVALIAÇÃO DA EDUCAÇÃO (CAEd). SPAECE - o sistema. 2020. Disponível em: http://www.spaece.caedufjf.net/. Acesso em: 20 nov. 2020.

CESGRANRIO. Quem somos. Uma história de sucessos e realizações. Disponível em: http://www.cesgranrio.org.br/institucional/quem_somos.aspx. Acesso em: 18 jun. 2020.

COELHO, M. I. C. A. Rede de cooperação entre escolas: uma ação no âmbito do Programa Alfabetização na Idade Certa - PAIC. 2013. Dissertação (Mestrado em Gestão e Avaliação da Educação) - Centro de Políticas Públicas e Avaliação da Educação (CAEd), Universidade Federal de Juíz de Fora, Juíz de Fora, 2013.

CORREA, E. V. Accountability na educação: Impactos do Prêmio Escola Nota Dez no sistema público de ensino do Ceará. 2018. Tese (Doutorado em Educação) - Pontifícia Universidade Católica do Rio de Janeiro, Rio de Janeiro, 2018. 
COSTA, A. G. A política educacional cearense no (des)compasso da accountability. 2020. Dissertação (Mestrado em Educação) - Universidade Estadual do Ceará, Fortaleza, 2020.

DANTAS, L. M. Avaliação externa e prática docente: o caso do Sistema Permanente de Avaliação da Educação Básica do Ceará (SPAECE) em uma escola em Maracanaú-CE. 2015. Dissertação (Mestrado em Educação Brasileira) - Faculdade de Educação, Universidade Federal do Ceará, Fortaleza, 2015.

EVANGELISTA, O. Apontamentos para o trabalho com documentos de política educacional. In: ARAÚJO, R. M. L.; RODRIGUES, D. S. (org.). A pesquisa em trabalho, educação e políticas educacionais. Campinas, SP: Alínea, 2012. v. 1, p. 52-71.

FREITAS, D. N. T. A avaliação da educação básica no Brasil: dimensão normativa, pedagógica e educativa. Campinas, SP: Autores e Associados, 2007.

MAGALHÃES JÚNIOR, A. G.; LIMA, D.; FARIAS, M. A. Política de avaliação educacional no Estado do Ceará: histórico dos programas de avaliação da Secretaria de Educação Básica do Ceará (SEDUC). Tópicos Educacionais, Recife, v. 19, n. 2, p. 54-75, jul./dez. 2013. DOl: https://doi.org/10.51359/24480215.2013.22369. Disponível em:

https://periodicos.ufpe.br/revistas/topicoseducacionais/article/view/22369. Acesso em: 25 abr. 2020.

NOBRE, M. C. Q. Modernização do atraso: a hegemonia burguesa do CIC e as alianças eleitorais da "Era Tasso". 2008. Tese (Doutorado em Sociologia) Universidade Federal do Ceará (UFC), Fortaleza, 2008.

OLIVEIRA, D. A.; CLEMENTINO, A. M. As políticas de responsabilização na educação básica nos estados do nordeste. In: OLIVEIRA, D. A.; DUARTE, A. M. C.; RODRIGUES, C. M. L. (org.). A política educacional em contexto de desigualdade: uma análise das redes públicas de ensino da região Nordeste. Campinas/SP: Mercado de Letras, 2019, p. 523-562.

OLIVEIRA, G. S. O programa de formação continuada para gestores escolares da CEFEB e seus efeitos na gestão das escolas municipais do Estado do Ceará. 2018. Tese (Doutorado em Educação) - Faculdade de Educação, Universidade Federal do Ceará, Fortaleza, 2018.

RAMOS, J. F. P. et al. Gestão por resultados na educação: a responsabilização e o regime de colaboração na promoção do direito à educação no Ceará (1995-2014). Relatório final do grupo de pesquisa Educação, Cultura Escolar e Sociedade. Redenção: Universidade da Integração Internacional da Lusofonia Afro-Brasileira - UNILAB, 2018. 
RAMOS, J. F. P.; LIRA, L. M.; SOARES, B. I. B. A reforma do Estado e modernização da gestão da educação básica no Ceará (1995-2006). HOLOS, ano 28, v. 2, 2012. DOI: https://doi.org/10.15628/holos.2012.880. Disponível em:

http://www2.ifrn.edu.br/ojs/index.php/HOLOS/article/view/880. Acesso em: 22 abr. 2020.

SCHNEIDER, M. P.; NARDI, E. L. Accountability em educação: mais regulação da qualidade ou apenas um estágio do Estado-avaliador? ETD - Educação Temática Digital, v. 17, n. 1, p. 58-74, jan-abr. 2015. DOI:

https://doi.org/10.20396/etd.v17i1.8634818. Disponível em:

https://periodicos.sbu.unicamp.br/ojs/index.php/etd/article/view/8634818.

Acesso em: 22 abr. 2020.

VALDEVINO, F. G. Políticas de Accountability como estratégia para a consolidação do gerencialismo na educação pública cearense (2007-2014). 2018. Dissertação (Mestrado em Educação) - Universidade Federal de Campina Grande, Campina Grande - PB, 2018.

Recebido em: 13 de outrubro de 2021.

Aprovado em: 19 de novembro de 2021.

Publicado em: 20 de novembro de 2021. 